Article

\title{
Gastrointestinal Stromal Tumours (GIST) in Young Adult (18-40 Years) Patients: A Report from the Dutch GIST Registry
}

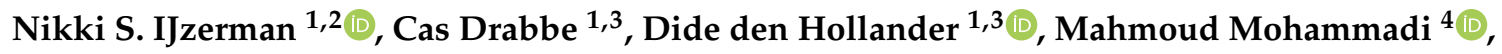 \\ Hester van Boven ${ }^{5}$, Ingrid M. E. Desar ${ }^{3}$, Hans Gelderblom ${ }^{4}{ }^{\mathbb{D}}$, Dirk J. Grünhagen ${ }^{6}$, \\ An K. L. Reyners ${ }^{7}$, Max M. van Noesel ${ }^{8}$ (D, Ron H. J. Mathijssen ${ }^{2}$, Neeltje Steeghs ${ }^{1}$ and \\ Winette T. A. van der Graaf 1,3,*(D) \\ 1 Department of Medical Oncology, Netherlands Cancer Institute, Plesmanlaan 121, \\ 1066 CX Amsterdam, The Netherlands; n.ijzerman@nki.nl (N.S.I.); cas.drabbe@student.ru.nl (C.D.); \\ D.denHollander@radboudumc.nl (D.d.H.); n.steeghs@nki.nl (N.S.) \\ 2 Department of Medical Oncology, Erasmus MC Cancer Institute, Erasmus University Medical Center, \\ Doctor Molewaterplein 40, 3015 GD Rotterdam, The Netherlands; a.mathijssen@erasmusmc.nl \\ 3 Department of Medical Oncology, Radboud University Medical Center, Geert Grooteplein Zuid 10, \\ 6525 GA Nijmegen, The Netherlands; Ingrid.Desar@radboudumc.nl \\ 4 Department of Medical Oncology, Leiden University Medical Center, Albinusdreef 2, \\ 2300 RC Leiden, The Netherlands; M.Mohammadi@lumc.nl (M.M.); A.J.Gelderblom@lumc.nl (H.G.) \\ 5 Department of Pathology, Netherlands Cancer Institute, Plesmanlaan 121, \\ 1066 CX Amsterdam, The Netherlands; h.v.boven@nki.nl \\ 6 Department of Surgical Oncology, Erasmus MC Cancer Institute, Erasmus University Medical Center, \\ Doctor Molewaterplein 40, 3015 GD Rotterdam, The Netherlands; d.grunhagen@erasmusmc.nl \\ 7 Department of Medical Oncology, University Medical Center Groningen, University of Groningen, \\ Hanzeplein 1, 9713 GZ Groningen, The Netherlands; a.k.l.reyners@umcg.nl \\ 8 Department of Solid Tumors, Princess Maxima Center for Pediatric Oncology, Heidelberglaan 25, \\ 3584 CS Utrecht, The Netherlands; M.m.vanNoesel@prinsesmaximacentrum.nl \\ * Correspondence: w.vd.graaf@nki.nl; Tel: +31-20-512-6979
}

Received: 24 February 2020; Accepted: 18 March 2020; Published: 20 March 2020

\begin{abstract}
Gastrointestinal stromal tumour (GIST) is a disease of older adults and is dominated by KIT/PDGFR mutations. In children, GIST is rare, predominantly occurs in girls, has a stomach location and generally lacks KIT/PDGFR mutations. For young adults (YA), aged 18 to 40 years, the typical phenotypic and genotypic patterns are unknown. We therefore aimed to describe the clinical, pathological and molecular characteristics of GIST in in YA. YA GIST patients registered in the Dutch GIST Registry (DGR) were included, and data were compared to those of older adults (OA). From 1010 patients in the DGR, 52 patients were YA (54\% male). Main tumour locations were stomach $(46 \%)$ and small intestine (46\%). GIST genetic profiles were mutations in KIT (69\%), PDGFRA (6\%), SDH deficient $(8 \%)$, NF1 associated (4\%), ETV6-NTRK3 gene fusion (2\%) or wildtype (10\%). Statistically significant differences were found between the OA and YA patients (localisation, syndromic and mutational status). YA presented more often than OA in an emergency setting (18\% vs. $9 \%$ ). The overall five-year survival rate was $85 \%$. In conclusion, YA GISTs are not similar to typical adult GISTs and also differ from paediatric GISTs, as described in the literature. In this series, we found a relatively high percentage of small intestine GIST, emergency presentation, 25\% non-KIT/PDGFRA mutations and a relatively good survival.
\end{abstract}

Keywords: GIST; young-adult patients; mutations; treatment; outcome 


\section{Introduction}

Gastrointestinal stromal tumours (GISTs) are found throughout the gastrointestinal tract and arise from interstitial cells of Cajal [1]. Their estimated incidence is 10-15 per million [2]. GIST patients have a median age at diagnosis of 65 years, and less than 10\% are diagnosed before the age of 40 [3-5].

The distinct presentation of paediatric GISTs is well described in the literature. While GISTs in adults arise in the stomach (40-60\%) or in the small intestine (25-40\%), in children, the stomach (90\%) is the predominant site of origin, and multifocal GISTs are common [6,7]. Furthermore, in children, GISTs have a female predilection [8] and are more often associated with genetic syndromes, such as the Carney-Stratakis syndrome, Carney's triad syndrome and Neurofibromatosis type 1 (NF1) [9-11].

Regarding mutational status, adult GISTs are commonly driven by activating mutations in either the KIT proto-oncogene (75\%) or the PDGFRA (platelet-derived growth factor receptor A) oncogene $(15 \%)[1,12,13]$, and 10\% were formerly named wildtype (WT) for KIT and PDGFRA [14]. However, genetic research has unveiled other sporadic genetic alterations leading to GISTs, including RAS pathway gene mutations and mutations in the four succinate dehydrogenase (SDH) subunits [15-17]. Therefore, the description WT GIST is disappearing, and it is now common practice for oncologists to describe which genetic alterations patients have been tested for [18]. In contrast to the molecular characteristics of adults with GIST, children are KIT and PDGFRA WT in the vast majority (85-90\%) [7,19-22]. Finally, metastases in adults are mostly located intra-abdominally [1,23], whereas, in children, lymph node and lung metastases are more common [24].

In addition to the classical paediatric and adult GIST presentation as defined above, a rare 'paediatric-type' presentation of GIST in (young) adults has been described in the literature, as well. Despite their adult age, these 'paediatric-type' GISTs are KIT/PDGFR WT and present with gastric lesions with multinodular or plexiform growth pattern and epithelioid or mixed cell histology. The 'paediatric-type' GIST predominantly affects women, often metastasizes to the lymph nodes and has a relatively indolent course of disease [25].

The young adult (YA) population has gained recognition in oncological research as a group with not only specific psychosocial needs but also distinct biological features [26-28]. The literature on both clinical and biological GIST characteristics in YA is scarce. This retrospective cohort study aims to describe the clinical, pathological and molecular characteristics of GIST in YA patients.

\section{Results}

\subsection{Patient Characteristics}

From 1010 patients registered in the Dutch GIST Registry (DGR) in March 2019, 52 YA patients (aged 18 to 40 years, 5\%) were identified (Table 1). A small majority was male (54\%), and the median age at diagnosis was 35 years (range 18-40). The main primary tumour locations were stomach (46\%) and small intestine (ileum/jejunum/duodenum, 46\%); median tumour size at diagnosis was $60 \mathrm{~mm}$; and 87\% had local disease at diagnosis. Two patients had multifocal GIST: one patient with a germline mutation (small bowel) and one patient without a known familial syndrome (stomach). Four YA patients had a known genetic predisposition for GIST, and three patients had a second malignancy (one patient had melanoma, one patient malignant peripheral neural sheath tumour (MPNST) and one patient also had breast and thyroid cancer). Most of the metastases that occurred were intra-abdominal/peritoneal or in the liver, with only one case of lymph node metastases. The most common symptom was active gastrointestinal bleeding (22\%). In eight asymptomatic patients, the GIST was a coincidental finding. According to the Miettinen risk classification, 21 patients had at baseline a high-risk tumour (41\%). 
Table 1. Clinical and tumour characteristics of total young-adult (YA) age group.

\begin{tabular}{|c|c|}
\hline Characteristic & Total $(\%)$ \\
\hline No. of YA Patients & $52(100)$ \\
\hline Median age at Diagnosis (Range) & 35 years $(18-40)$ \\
\hline \multicolumn{2}{|l|}{ Gender } \\
\hline Male & $28(53.8)$ \\
\hline Female & $24(46.2)$ \\
\hline Median Baseline Tumour Size in mm (Range) & $60(6-370)$ \\
\hline \multicolumn{2}{|l|}{ Location } \\
\hline Gastric & $24(46.2)$ \\
\hline Small intestine & $24(46.2)$ \\
\hline Rectum & $3(5.8)$ \\
\hline Oesophageal-cardiac junction & $1(1.9)$ \\
\hline \multicolumn{2}{|l|}{ Syndromic Presentation } \\
\hline No & 39 (90.7) \\
\hline Yes & $4(9.3)$ \\
\hline Neurofibromatosis 1 & 2 \\
\hline Carney triad & 1 \\
\hline KIT exon 11 germline mutation & 1 \\
\hline Unknown & 9 \\
\hline \multicolumn{2}{|l|}{ Symptoms at Diagnosis * } \\
\hline Active gastrointestinal bleeding & $11(22.4)$ \\
\hline Abdominal pain & $9(18.4)$ \\
\hline Weight loss & $9(18.4)$ \\
\hline Mass related symptoms (e.g., reflux, palpable mass, distended abdomen) & $7(14.3)$ \\
\hline Anaemia related symptoms & $6(12.2)$ \\
\hline Acute abdomen & $6(12.2)$ \\
\hline Nausea/vomiting & $4(8.2)$ \\
\hline Change in bowel habits & $3(6.1)$ \\
\hline Analysis vitamin B12 deficiency & $1(2.0)$ \\
\hline None (GIST coincidental finding) & $8(16.3)$ \\
\hline Unknown & 3 \\
\hline \multicolumn{2}{|l|}{ Second Malignancies } \\
\hline No & $49(94.2)$ \\
\hline Yes & $3(5.8)$ \\
\hline \multicolumn{2}{|l|}{ Tumour Status at Diagnosis } \\
\hline Local disease & $45(86.5)$ \\
\hline Metastasized & $7(13.5)$ \\
\hline \multicolumn{2}{|l|}{ Risk Classification } \\
\hline None & $2(3.9)$ \\
\hline Low & $19(37.3)$ \\
\hline Moderate & $9(17.6)$ \\
\hline High & $21(41.2)$ \\
\hline Unknown & 1 \\
\hline
\end{tabular}

${ }^{*}$ Multiple symptoms at diagnosis possible. GIST = Gastrointestinal stromal tumour.

\subsection{Pathology}

The histology of the primary tumours was predominantly spindle cell $(76 \%)$, and the baseline mitotic rate was low in 69\% (Table 2). GIST genetic profiles were reported as KIT mutation 69\%, PDGFRA mutation 6\%, SDH deficient 8\%, NF1 associated 4\%, ETV6-NTRK3 (translocation-Ets-leukaemia virus and neurotrophic tyrosine kinase, only tested in one of the WT patients) gene fusion $2 \%$, quadruple WT $6 \%$, triple WT $2 \%$ and KIT/PDGFRA WT $2 \%$. The WT tumours were located in the stomach $(4 / 5)$ and in the small intestine (1/5). Altogether, $25 \%$ of the patients had a non-KIT/PDGFR mutation. One patient had a double primary mutation: KIT exon 11 and KIT exon 9.

\subsection{Treatment}

Patients in Dutch GIST centres are generally treated according to standard guidelines. Of all YA patients in this cohort, 14 received neoadjuvant treatment (30\%). Of the 45 patients with localized disease, three did not undergo surgery, as a result of progressive disease on neoadjuvant therapy 
(two) or comorbidities (one). Two patients received surgery of their primary tumour in the metastatic, emergency setting. In total, 44 patients underwent surgery of the primary tumour (85\%) (Figure 1). In eight patients, emergency surgery was performed due to perforation or active bleeding (six small intestine; two gastric). The resection margins were microscopically free from tumour in $93 \%$, and five patients $(11 \%)$ had complications, with none requiring further surgery. Of the 44 surgically treated patients, seven patients received neoadjuvant and adjuvant treatment and 12 received adjuvant treatment only.

Table 2. Pathology and tumour genetic results of young-adult patients.

\begin{tabular}{cc}
\hline Characteristic & No. (\%) \\
Histology & \\
Spindle cell & $37(75.5)$ \\
Epithelioid & $3(6.1)$ \\
Mixed type & $9(18.4)$ \\
Not reported & 3 \\
Baseline Mitotic Rate & \\
Low $\left(\leq 5 / 5 \mathrm{~mm}^{2}\right)$ & $35(68.6)$ \\
High $\left(>5 / 5 \mathrm{~mm}^{2}\right)$ & $16(31.4)$ \\
Unknown & 1 \\
Mutation Status & \\
KIT & $34(69.4)$ \\
Exon $11 *$ & 32 \\
Exon 9 & 3 \\
PDGFRA D842V & $3(6.1)$ \\
Non-D842V & 2 \\
SDH deficiency & 1 \\
NF1 associated & $4(8.2)$ \\
ETV6-NTRK3 gene fusion & $2(4.1)$ \\
KIT/PDGFA (BRAF and/or SDH not performed) & $1(2.0)$ \\
Triple WT (SDH not performed) & $1(2.0)$ \\
Quadruple WT & $1(2.0)$ \\
No mutational analysis performed & $3(6.1)$ \\
NT & 3 \\
\hline
\end{tabular}

* One patient had both an exon 11 and exon 9 mutation in the primary tumour. NF1 = neurofibromatosis type 1; $\mathrm{WT}=$ wildtype.

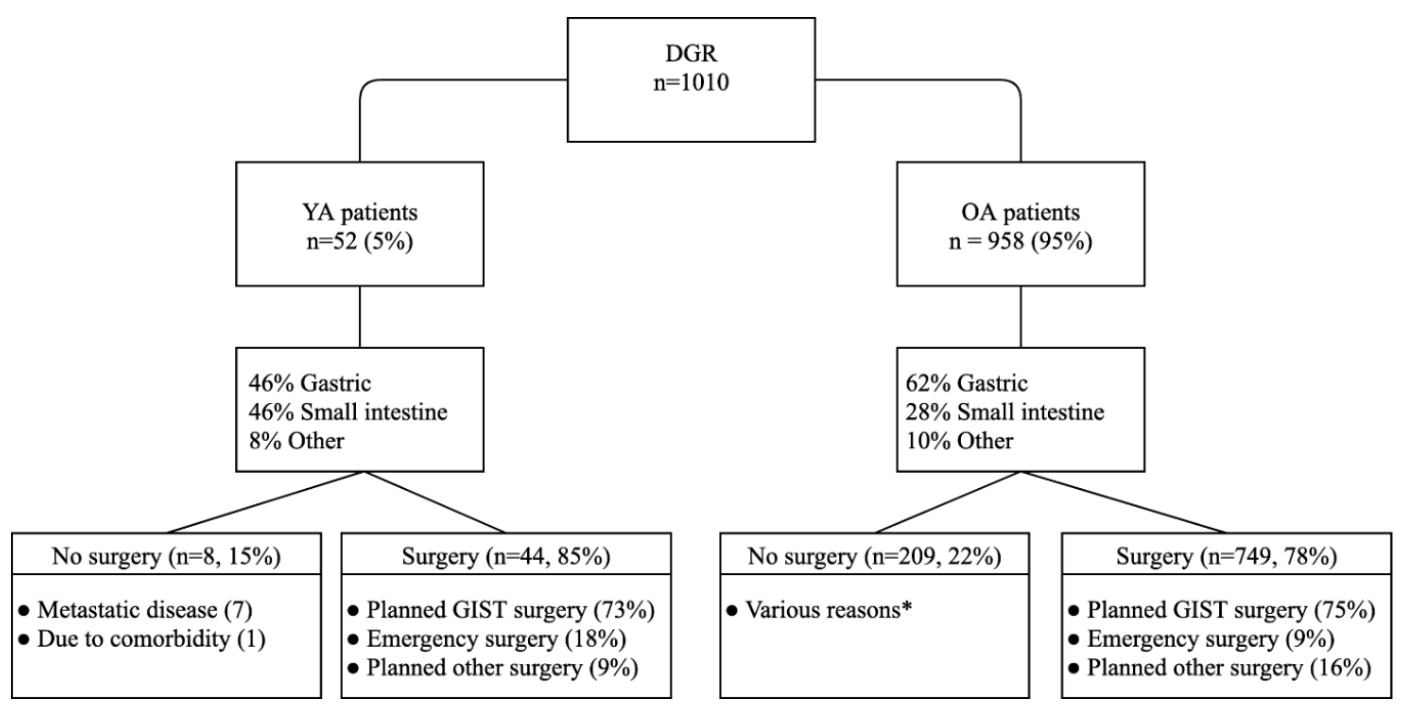

Figure 1. Study flowchart. * various reasons, such as metastatic disease, significant comorbidity, irresectable tumours or patients' preference. DGR = Dutch GIST Registry; YA = young adult; $\mathrm{OA}=$ older adult. 


\subsection{Outcome}

With a median follow-up time of 52 months (95\% Confidence Interval (CI): 31.5-72.5), the median overall survival (OS) for the YA patients was 8.9 years (95\% CI: 7.4-10.4), with an estimated five-year survival rate of $85 \%$ (95\% CI: 71.6-97.5). Of the 44 patients with resection of the primary tumour, $13(30 \%)$ developed recurrence: two local, eight distant and three both local and distant recurrences.

The median follow-up time in older adults (OA) was 37 months (95\% CI: 33.0-41.0). The median OS time was not reached, but the estimated five-year survival rate was 76\% (95\% CI: 72.2-79.7). There was no significant difference in OS between the YA and OA patients $(p=0.10)$ (Figure 2).

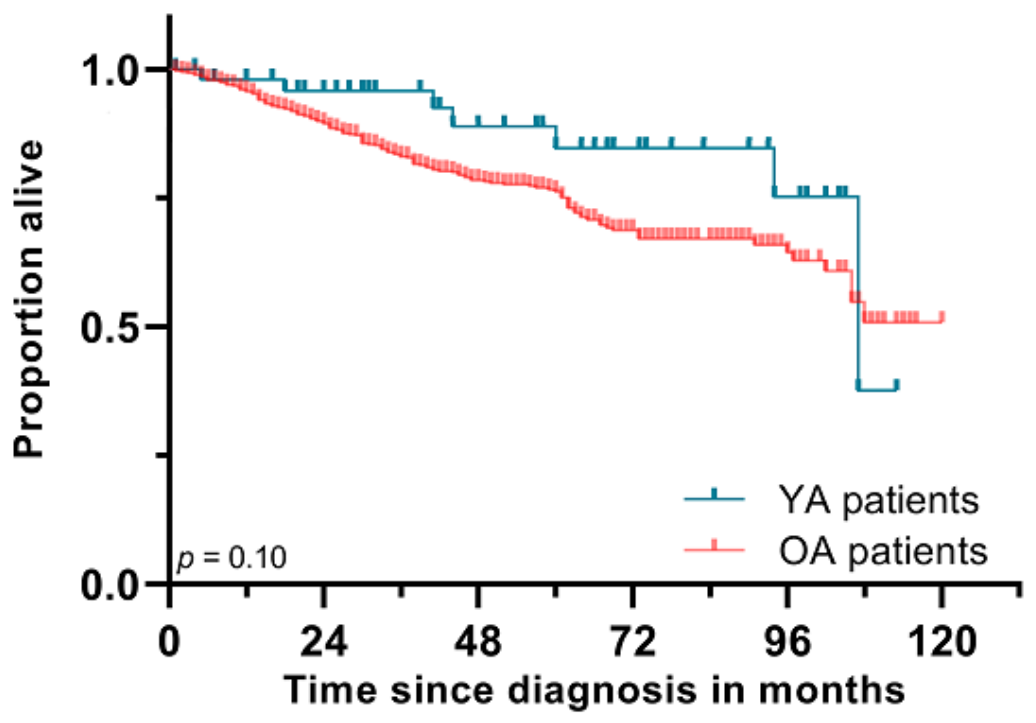

$\begin{array}{lcllcccl}\text { No. at risk } & \mathbf{O} & \mathbf{N} & & & & & \\ \text { YA patients: } & 7 & 52 & 38 & 24 & 14 & 6 & 0 \\ \text { OA patients: } & 168 & 946 & 538 & 296 & 124 & 43 & 0\end{array}$

Figure 2. Overall survival curve of the young adult (YA) patients and older adult (OA) patients. $\mathrm{O}=$ number of observed events; $\mathrm{N}=$ number of patients at risk.

\subsection{Impact of GIST on Life}

In $56 \%$ of all patients, the psychosocial impact of their disease on life was both discussed by the oncologist and noted in the electronic patient record (EPR). This was $15 \%$ for the possible influence of the disease or treatment on fertility. The (in)ability to work/study was discussed and noted in 12 $(46 \%)$ of the 26 patients receiving (neo) adjuvant therapy; seven patients (58\%) had no limitations, four reported to be working/studying less than before diagnosis; and one could no longer continue work/study. For the 18 YA patients treated in the palliative setting, (in)ability to work/study was discussed and noted in eight $(44 \%)$, of which one (13\%) reported no limitations; five were $(63 \%)$ studying/working less than before; and two (25\%) stopped working/studying altogether. Eleven patients were referred to a clinical geneticist.

\subsection{Comparison of Age Groups}

\subsubsection{Comparison within the YA Cohort}

Group 1 (age 18-29 years, median 26) consisted of 15 patients, and group 2 (30-40 years, median 38) of 37 patients. No significant differences in clinical and tumour characteristics were found between the two YA age subgroups (Table 3). Furthermore, no differences were found in OS ( $p=0.81)$ nor in RFS ( $p=0.75$ ). Concerning the mutation distribution among the YA cohort, no clear turning point was found where more wildtypes in younger patients (as in paediatric population) shifted to more KIT mutated patients in older patients (as in adult population) (Figure 3). 
Table 3. Clinical and tumour characteristics within the young-adult age group.

\begin{tabular}{|c|c|c|c|}
\hline Characteristic & $\begin{array}{l}\text { 18-29 Years } \\
(n=15)\end{array}$ & $\begin{array}{l}30-40 \text { Years } \\
\quad(n=37)\end{array}$ & $p$-Value \\
\hline Median Age at Diagnosis (Range) & $26(18-29)$ & $38(30-40)$ & \\
\hline Gender & & & 0.07 \\
\hline Male & $5(33.3)$ & $23(62.2)$ & \\
\hline Female & $10(66.6)$ & $14(37.8)$ & \\
\hline $\begin{array}{c}\text { Median Baseline Tumour Size in mm } \\
\text { (Range) }\end{array}$ & $45(14-170)$ & $60(6-370)$ & 0.23 \\
\hline Primary Site Grouped & & & 0.48 \\
\hline Gastric & $5(33.3)$ & $19(51.4)$ & \\
\hline Small intestine & $9(60.0)$ & $15(40.5)$ & \\
\hline Other & $1(6.7)$ & $3(8.1)$ & \\
\hline Histology & & & 0.74 \\
\hline Spindle cell & $12(80.0)$ & $24(73.5)$ & \\
\hline Epithelioid & $0(0.0)$ & $3(8.8)$ & \\
\hline Mixed type & $3(20.0)$ & $6(17.6)$ & \\
\hline Unknown & 0 & 3 & \\
\hline Tumour Status at Diagnosis & & & 1.00 \\
\hline Local disease & $13(87.7)$ & $32(86.5)$ & \\
\hline Metastasized & $2(13.3)$ & $5(13.5)$ & \\
\hline Risk Category & & & 0.53 \\
\hline Low/moderate & $7(46.7)$ & $23(62.2)$ & \\
\hline High & $7(53.3)$ & $14(37.8)$ & \\
\hline Unknown & 1 & 0 & \\
\hline Mutation Status & & & 0.72 \\
\hline KIT & $10(66.7)$ & $24(70.6)$ & \\
\hline PDGFRA & $0(0.0)$ & $3(8.8)$ & \\
\hline SDH deficient & $2(13.3)$ & $2(5.9)$ & \\
\hline NF1 associated & $1(6.7)$ & $1(2.9)$ & \\
\hline ETV6-NTRK3 gene fusion & $0(0.0)$ & $1(2.9)$ & \\
\hline WT (min. KIT and PDGFRA) & $2(13.3)$ & $3(8.8)$ & \\
\hline Unknown & 0 & 3 & \\
\hline Baseline Mitotic Rate & & & 0.32 \\
\hline Low $\left(\leq 5 / 5 \mathrm{~mm}^{2}\right)$ & $8(57.1)$ & $27(73.0)$ & \\
\hline $\operatorname{High}\left(>5 / 5 \mathrm{~mm}^{2}\right)$ & $6(42.9)$ & $10(27.0)$ & \\
\hline Unknown & 1 & 0 & \\
\hline Surgery & & & 0.41 \\
\hline Yes & $14(93.3)$ & $30(81.1)$ & \\
\hline No & $1(6.7)$ & $7(18.9)$ & \\
\hline Patients who Received Surgery & $14(93.3)$ & $30(81.1)$ & 0.41 \\
\hline Resection Margin & & & 0.26 \\
\hline Negative (R0) & $12(85.7)$ & $27(96.4)$ & \\
\hline Positive (R1/R2) & $2(14.3)$ & $1(3.6)$ & \\
\hline Unknown & 0 & 2 & \\
\hline Tumour Rupture & & & 1.00 \\
\hline No & $11(84.6)$ & $24(80.0)$ & \\
\hline Yes & $2(15.4)$ & $5(20.0)$ & \\
\hline Unknown & 1 & 1 & \\
\hline
\end{tabular}

NF1 = neurofibromatosis type $1 ; \mathrm{WT}=$ wildtype.

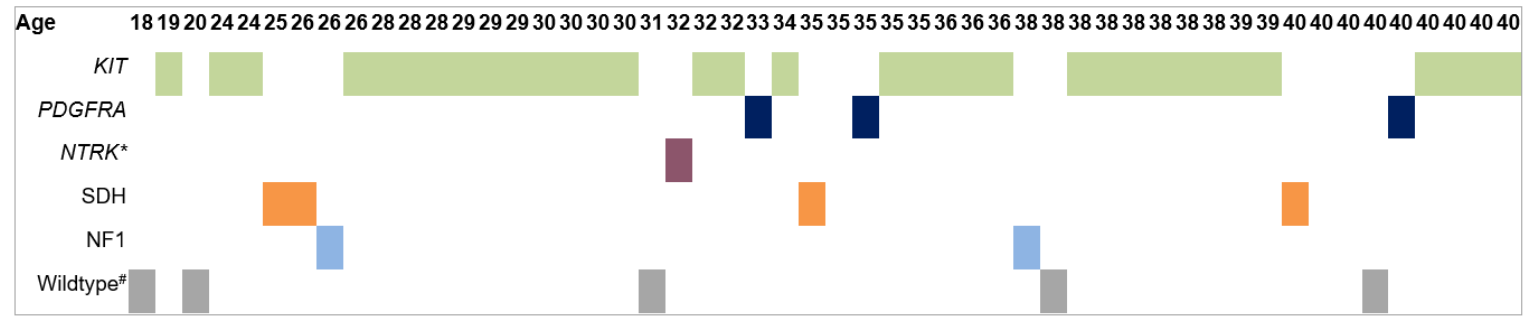

Figure 3. Distribution of mutation status among our young adult cohort ${ }^{*} E T V 6-N T R K 3$ gene fusion. \# Wildtype for at least KIT and PDGFR. 


\subsubsection{Comparison between the YA and OA Patients}

The OA age group consisted of 958 patients (Table 4). Tumours were significantly more often localized in the small intestine in the YA age group, as compared to the OA age group (46\% vs. $28 \%$, $p=0.03)$. YA patients had a syndromic presentation more often than the OA age group $(p=0.047)$. Furthermore, YA patients significantly more often had non-KIT/PDGFRA positive tumours than patients in the OA group ( $25 \%$ vs. $11 \%$, respectively; $p=0.008)$. Concerning treatment, YA patients tended to have surgery in an emergency setting more often than OA patients ( $18 \%$ vs. $9 \%, p=0.06)$ (Figure 1). YA patients did not present more often with metastatic disease compared to OA ( $13.5 \%$ vs. $24.6 \%, p=0.09)$. Furthermore, no significant differences were found between the two groups in gender, primary tumour size, risk classification, histology, baseline mitotic rate or the number of patients receiving surgery.

Table 4. Clinical and tumour characteristics in the young adult (YA) and older adult (OA) age groups.

\begin{tabular}{|c|c|c|c|c|}
\hline Characteristic & $\begin{array}{l}\text { Total }(\%) \\
n=1010\end{array}$ & $\begin{array}{l}\text { YA (\%) } \\
n=52\end{array}$ & $\begin{array}{l}\text { OA (\%) } \\
n=958\end{array}$ & $p$-Value \\
\hline Median Age at Diagnosis (range) & $64(18-95)$ & $35(18-40)$ & $65(41-95)$ & \\
\hline Gender & & & & 0.89 \\
\hline Male & $533(52.8)$ & $28(53.8)$ & $505(52.7)$ & \\
\hline Female & $477(47.2)$ & $24(46.2)$ & 453 (47.3) & \\
\hline $\begin{array}{c}\text { Median Baseline Tumour Size in } \mathrm{mm} \\
\text { (Range) }\end{array}$ & $72(1-1000)$ & $60(6-370)$ & $73(1-1000)$ & 0.09 \\
\hline Primary Site Grouped & & & & $0.03 *$ \\
\hline Gastric & $604(60.7)$ & $24(46.2)$ & $580(61.5)$ & \\
\hline Small intestine & $290(29.1)$ & $24(46.2)$ & $266(28.2)$ & \\
\hline Other & $101(10.2)$ & $4(7.7)$ & $91(10.3)$ & \\
\hline Syndromic Presentation & & & & 0.047 * \\
\hline No & 799 (96.7) & $39(90.7)$ & $760(97.1)$ & \\
\hline Yes & $27(3.3)$ & $4(9.3)$ & $23(2.9)$ & \\
\hline Unknown & 184 & 9 & 175 & \\
\hline Tumour Status at Diagnosis & & & & 0.09 \\
\hline Local disease & $767(76.0)$ & $45(86.5)$ & $722(75.4)$ & \\
\hline Metastasized & $242(24.0)$ & $7(13.5)$ & $235(24.6)$ & \\
\hline Unknown & 1 & 0 & 1 & \\
\hline Histology & & & & 0.26 \\
\hline Spindle cell & 739 (78.3) & $37(75.5)$ & $702(78.4)$ & \\
\hline Epithelioid & $94(10.0)$ & $3(6.1)$ & $91(10.2)$ & \\
\hline Mixed type & $111(11.8)$ & $9(18.4)$ & $102(11.4)$ & \\
\hline Unknown & 66 & 3 & 63 & \\
\hline Baseline Mitotic Rate & & & & 0.76 \\
\hline $\operatorname{Low}\left(\leq 5 / 5 \mathrm{~mm}^{2}\right)$ & $491(66.4)$ & $35(68.6)$ & $462(66.2)$ & \\
\hline $\operatorname{High}\left(>5 / 5 \mathrm{~mm}^{2}\right)$ & $252(33.6)$ & $16(31.4)$ & $236(33.8)$ & \\
\hline Unknown & 261 & 1 & 260 & \\
\hline Mutation Status & & & & $0.001 *$ \\
\hline KIT & $630(75.9)$ & $34(69.4)$ & $596(76.3)$ & \\
\hline PDGFRA & $106(12.8)$ & $3(6.1)$ & $103(13.2)$ & \\
\hline$B R A F$ & $1(0.1)$ & 0 & $1(0.1)$ & \\
\hline SDH deficiency & $13(1.6)$ & $4(8.2)$ & $9(1.2)$ & \\
\hline NF1 associated & $16(1.9)$ & $2(4.1)$ & $14(1.8)$ & \\
\hline ETV6-NTRK3 gene fusion & $1(0.1)$ & $1(2.0)$ & 0 & \\
\hline Wildtype (at least KIT and PDGFRA) & $63(7.6)$ & $5(10.2)$ & $58(7.4)$ & \\
\hline Unknown & 180 & 3 & 177 & \\
\hline KIT/PDGFRA vs. non-KIT/PDGFRA & & & & $0.008 *$ \\
\hline KIT/PDGFRA & $736(88.7)$ & $37(75.5)$ & $699(89.5)$ & \\
\hline Non-KIT/PDGFRA & $94(11.3)$ & $12(24.5)$ & $82(10.5)$ & \\
\hline Patients who Received Surgery & $793(78.5)$ & $44(84.6)$ & 749 (78.2) & 0.30 \\
\hline Surgery Setting & & & & 0.06 \\
\hline Planned operation & $712(90.7)$ & $36(81.8)$ & $676(91.2)$ & \\
\hline Emergency setting & $73(9.3)$ & $8(18.2)$ & $65(8.8)$ & \\
\hline Unknown & 8 & 0 & 8 & \\
\hline
\end{tabular}

* $p$-value $<0.05$ was considered significant; NF1 = neurofibromatosis type 1. 


\section{Discussion}

This study shows that GIST at YA age is rare, representing only $5 \%$ of a large database. Paediatric GISTs have a female predilection and are rarely KIT/PDGFRA mutated [6]. With an almost equal gender distribution and increased presence of KIT or PDGFRA mutations, YA GISTs differ from paediatric GIST. However, YA GISTs are also not fully similar to the typical adult GISTs either, as they have a lower percentage of KIT and PDGFRA mutations (76\% vs. 90\%) and are more frequently located in the small intestine ( $46 \%$ vs. $28 \%$ ). Within the YA age group, we could not demonstrate a clear turning point in age at which the mutational status shifted from WT to KIT/PDGFRA mutation, but that may be due to the still relatively small number of YA patients.

Comparison of the data from this study with age-related GIST data in the existing literature is challenging. This is due to the scarcity of GIST data in the YA population, the divergent composition of age-groups studied and the incomplete reporting on mutational status. Three studies reported on individual patients, and we used these data to construct a YA (18-29) and a paediatric age group $(<18)[19,22,29]$. Fero et al. studied a large AYA population (13-39) and an OA population $(\geq 40)$; however, they did not report on mutational status [30] (Supplementary Table S1). The almost-equal gender distribution in the YA and OA cohort of this study is in accordance with the large AYA and OA population studied by Fero et al. [30]. Small intestine localisation seems to be less prevalent in the OA population compared with the YA population of this study, which is in line with the previous literature. Furthermore, this study confirmed that YA patients do not significantly more often present with metastatic disease compared to the OA population.

Concerning the mutational status, which was only scarcely reported before, our results were similar to the very small population $(n=30)$ of the combined studies of Prakash and Kang $[19,29]$. The amount of KIT and PDGFRA mutations does not seem to be as low as in paediatric patients, but also not as high as in OA patients. Since we found no clear turning point, there seems to be more evidence for a gliding scale, where an increase in age also increases the probability of a KIT/PDGFRA mutated GIST [31]. In two recent studies conducted in wildtype GIST patients, the reported median ages were 21 and 23 years, which supports the theory that most WT GISTs occur at a younger age [32,33].

In our cohort, YA GIST patients tended to undergo surgery more often in an emergency setting compared to OA. The relatively high percentage of small-intestine localisations might account for this [34]. Another possible explanation would be that the rarity of GIST at the YA age leads to a delay in (correct) diagnosis. Delay of diagnosis in sarcomas, especially at this age, remains a problem, and efforts to educate doctors and patients should be continued [35].

In over half of these young adults, the impact of the disease on life was not documented in their file and therefore possibly not discussed. For these YA patients who are diagnosed with cancer in the prime time of their lives, it is essential to take psychosocial factors (e.g., relationships, fertility, sexuality, financial toxicity and workability) into account. With a five-year survival of $85 \%$, these survivorship issues are not trivial.

The five-year OS reported in this study is in line with the $82.4 \%$ five-year OS reported by Fero et al. in a large cohort of AYA patients aged 13-39, with GIST [30]. A study conducted in elderly ( $\geq 75$ years) GIST patients reported a median OS of just 34 months [31]. The five-year survival rate of YA in our cohort seemed superior to the survival rate of OA ( $85 \%$ vs. $76 \%)$, but this was not significant. Notably, there was a difference in median follow-up, and the influence of other age-related factors, such as comorbidities, was not corrected for and could also explain (a part of) the difference in survival rate.

As a side note, several Dutch databases with paediatric cancer patients were searched for GIST, and over the same time period, only one paediatric patient was diagnosed. This illustrates how extremely rare paediatric GIST is.

For future research, it would be interesting to compare separate molecular subgroups between the YA and OA patients, in order to find out if the differences between the age groups persist. However, since GIST in YA patients is rare, and molecular subgroups are therefore extremely small, this research question can only be answered in an international setting, with an adequate sample size. Although the 
data was obtained from the DGR, a database containing information on GIST patients diagnosed for 10 years, the rarity of YA GIST makes that the numbers are still relatively small. Moreover, when the DGR was established, it was not common practice to test for NTRK fusion genes and BCOR gene mutations. Despite these limitations, this study on YA GIST is the largest series of a national population, including mutational status. Given its therapeutic implications, it is recommended to test from now on the quadruple WT GISTs for NTRK (neurotrophic tyrosine kinase) fusion genes as part of standard care.

\section{Materials and Methods}

\subsection{Patient Selection and Variables}

All patients who were 18 to 40 years old at diagnosis, who were diagnosed with GIST between January 2009 and January 2019 and who were registered in the Dutch GIST Registry (DGR) were included. The DGR is a prospectively maintained database, including patients $\geq 18$ years with GIST treated in one of the five Dutch GIST centres (LUMC Leiden, Erasmus MC Rotterdam, UMC Groningen, Radboud UMC Nijmegen and the Netherlands Cancer Institute Amsterdam). Patient (age, gender, symptoms at diagnosis, presence of second malignancies and syndromic presentation), tumour (location, size, status at diagnosis (e.g., localized disease or metastatic disease), pathology (histology, mitotic rate and mutation status), treatment (surgery yes/no, surgery setting (e.g., emergency setting, planned operation for GIST and planned other surgery), (neo)adjuvant therapy yes/no) and follow-up data were obtained from the database. Furthermore, clinical, treatment and outcome data of all older adults (OA, $>40$ years old) were collected from the DGR, to compare data between OA and YA. Within the comparison of tumour location, locations with less than 100 patients in the OA group were classified as 'other'. The DGR was approved by the local independent ethics committee (PTC14.0057). We adhered to the STROBE guidelines for cohort studies.

\subsection{Pathology}

GIST diagnosis was confirmed by positive immunohistochemistry (IHC) for CD117 and/or DOG1. Histology was described as spindle cell, epithelioid cell or mixed cell type. The required total count of mitoses is per $5 \mathrm{~mm}^{2}$ on the glass slide section. With the use of older model microscopes, $50 \mathrm{HPF}$ was used which we considered semi-equivalent to $5 \mathrm{~mm}^{2}$. Low mitotic rate was defined as $\leq 5$ mitoses $/ 5 \mathrm{~mm}^{2}$ and high as $>5$ mitoses $/ 5 \mathrm{~mm}^{2}$. GIST specific mutations tested by Next Generation Sequencing (NGS) were KIT, PDGFRA and BRAF. Patients without KIT/PDGFRA/BRAF mutations and where no SDH analysis was performed were considered triple wildtype (WT). Patients without KIT/PDGFRA/BRAF mutations and SDHB deficiency (considered deficient in the absence of SDHB protein expression on IHC [36]) were considered quadruple WT. Based on size, tumour site and mitotic activity, patients were subdivided into risk classification groups according to Miettinen's criteria [37].

\subsection{Quality of Life}

In this YA cohort, it was explored how often the psychosocial impact on life (e.g., depression, body image and relationships), influence on fertility and (in)ability to work was documented explicitly in the EPR by the medical oncologist. Whether or not this had been discussed with a patient was purely based on documentation in the EPR. Data on referral to a clinical geneticist were also collected.

\subsection{Statistical Analyses and Outcome}

Statistical analyses were performed by using SPSS Statistics (IBM Corporation, version 25.0, Armonk, NY, USA). Survival estimates were obtained, using the Kaplan-Meier method, and compared by the log-rank test. Overall survival (OS) was calculated from the date of diagnosis to the date of death or last follow-up. Follow-up time was estimated with the reversed Kaplan-Meier method. Two subgroups within the YA group were compared: $18-29$ years vs. $30-40$ years. The comparative 
analyses were done by using Fisher's exact test for categorical variables or Mann-Whitney U test for numeric variables.

\section{Conclusions}

YA with GIST are rare and differ from OA with GIST, but they also differ from paediatric GIST, as described in the literature. In this series, YA patients had a relatively high percentage of small intestine localisation and relatively often presented in the acute setting. Absence of both KIT and PDGFRA mutations was seen in $25 \%$ of YA patients. A relatively favourable five-year OS of $85 \%$ was observed.

Supplementary Materials: The following is available online at http://www.mdpi.com/2072-6694/12/3/730/s1. Table S1: Adolescents and young adults (AYA) age-related GIST data in the existing literature.

Author Contributions: Conceptualization, W.T.A.v.d.G.; methodology, N.S.IJ. and W.T.A.v.d.G.; project administration, N.S.IJ., C.D., D.d.H., M.M. and M.M.v.N.; formal analysis, N.S.IJ.; data curation, N.S.IJ. and C.D.; writing - original draft preparation, N.S.IJ. and C.D.; writing-review and editing, W.T.A.v.d.G., D.d.H., M.M., H.v.B., N.S., R.H.J.M., H.G., I.M.E.D., M.M.v.N., D.J.G. and A.K.L.R.; visualization, C.D. and N.S.IJ.; supervision, W.T.A.v.d.G. All authors have read and agreed to the published version of the manuscript.

Funding: A research grant for the Dutch GIST Registry was received from Novartis (3017/13), Pfizer (WI189378), Bayer (2013-MED-12005) and Deciphera (4EE9EEC-7F19-484D-86A4-646CFE0950A5). These funding sources did not have any involvement in the conduction of this research.

Conflicts of Interest: The authors declare no conflict of interest. The funders had no role in the design of the study; in the collection, analyses, or interpretation of data; in the writing of the manuscript; or in the decision to publish the results.

\section{References}

1. Joensuu, H. Gastrointestinal stromal tumor (GIST). Ann. Oncol. 2006, 17 (Suppl. S10), x280-x286. [CrossRef] [PubMed]

2. Soreide, K.; Sandvik, O.M.; Soreide, J.A.; Giljaca, V.; Jureckova, A.; Bulusu, V.R. Global epidemiology of gastrointestinal stromal tumours (GIST): A systematic review of population-based cohort studies. Cancer Epidemiol. 2016, 40, 39-46. [CrossRef] [PubMed]

3. Miettinen, M.; Sobin, L.H.; Lasota, J. Gastrointestinal stromal tumors of the stomach: A clinicopathologic, immunohistochemical, and molecular genetic study of 1765 cases with long-term follow-up. Am. J. Surg. Pathol. 2005, 29, 52-68. [CrossRef] [PubMed]

4. Nilsson, B.; Bumming, P.; Meis-Kindblom, J.M.; Oden, A.; Dortok, A.; Gustavsson, B.; Sablinska, K.; Kindblom, L.G. Gastrointestinal stromal tumors: The incidence, prevalence, clinical course, and prognostication in the preimatinib mesylate era-A population-based study in western Sweden. Cancer 2005, 103, 821-829. [CrossRef] [PubMed]

5. Tryggvason, G.; Gislason, H.G.; Magnusson, M.K.; Jonasson, J.G. Gastrointestinal stromal tumors in Iceland, 1990-2003: The icelandic GIST study, a population-based incidence and pathologic risk stratification study. Int. J. Cancer 2005, 117, 289-293. [CrossRef]

6. Kaemmer, D.A.; Otto, J.; Lassay, L.; Steinau, G.; Klink, C.; Junge, K.; Klinge, U.; Schumpelick, V. The Gist of literature on pediatric GIST: Review of clinical presentation. J. Pediatr. Hematol. Oncol. 2009, 31, 108-112. [CrossRef]

7. Rink, L.; Godwin, A.K. Clinical and molecular characteristics of gastrointestinal stromal tumors in the pediatric and young adult population. Curr. Oncol. Rep. 2009, 11, 314-321. [CrossRef]

8. Quiroz, H.J.; Willobee, B.A.; Sussman, M.S.; Fox, B.R.; Thorson, C.M.; Sola, J.E.; Perez, E.A. Pediatric gastrointestinal stromal tumors-a review of diagnostic modalities. Transl. Gastroenterol. Hepatol. 2018, 3, 54. [CrossRef]

9. Diment, J.; Tamborini, E.; Casali, P.; Gronchi, A.; Carney, J.A.; Colecchia, M. Carney triad: Case report and molecular analysis of gastric tumor. Hum. Pathol. 2005, 36, 112-116. [CrossRef] 
10. Pasini, B.; McWhinney, S.R.; Bei, T.; Matyakhina, L.; Stergiopoulos, S.; Muchow, M.; Boikos, S.A.; Ferrando, B.; Pacak, K.; Assie, G.; et al. Clinical and molecular genetics of patients with the Carney-Stratakis syndrome and germline mutations of the genes coding for the succinate dehydrogenase subunits SDHB, SDHC, and SDHD. Eur. J. Hum. Genet. 2008, 16, 79-88. [CrossRef]

11. Gasparotto, D.; Rossi, S.; Polano, M.; Tamborini, E.; Lorenzetto, E.; Sbaraglia, M.; Mondello, A.; Massani, M.; Lamon, S.; Bracci, R.; et al. Quadruple-negative GIST is a sentinel for unrecognized neurofibromatosis type 1 syndrome. Clin. Cancer Res. 2017, 23, 273-282. [CrossRef] [PubMed]

12. Heinrich, M.C.; Corless, C.L.; Duensing, A.; McGreevey, L.; Chen, C.J.; Joseph, N.; Singer, S.; Griffith, D.J.; Haley, A.; Town, A.; et al. PDGFRA activating mutations in gastrointestinal stromal tumors. Science 2003, 299, 708-710. [CrossRef] [PubMed]

13. Hirota, S.; Isozaki, K.; Moriyama, Y.; Hashimoto, K.; Nishida, T.; Ishiguro, S.; Kawano, K.; Hanada, M.; Kurata, A.; Takeda, M.; et al. Gain-of-function mutations of c-kit in human gastrointestinal stromal tumors. Science 1998, 279, 577-580. [CrossRef] [PubMed]

14. Corless, C.L.; Barnett, C.M.; Heinrich, M.C. Gastrointestinal stromal tumours: Origin and molecular oncology. Nat. Rev. Cancer 2011, 11, 865-878. [CrossRef] [PubMed]

15. Pantaleo, M.A.; Astolfi, A.; Urbini, M.; Nannini, M.; Paterini, P.; Indio, V.; Saponara, M.; Formica, S.; Ceccarelli, C.; Casadio, R.; et al. Analysis of all subunits, SDHA, SDHB, SDHC, SDHD, of the succinate dehydrogenase complex in KIT/PDGFRA wild-type GIST. Eur. J. Hum. Genet. 2014, 22, 32-39. [CrossRef] [PubMed]

16. Daniels, M.; Lurkin, I.; Pauli, R.; Erbstosser, E.; Hildebrandt, U.; Hellwig, K.; Zschille, U.; Luders, P.; Kruger, G.; Knolle, J.; et al. Spectrum of KIT/PDGFRA/BRAF mutations and Phosphatidylinositol-3-Kinase pathway gene alterations in gastrointestinal stromal tumors (GIST). Cancer Lett. 2011, 312, 43-54. [CrossRef]

17. Flavahan, W.A.; Drier, Y.; Johnstone, S.E.; Hemming, M.L.; Tarjan, D.R.; Hegazi, E.; Shareef, S.J.; Javed, N.M.; Raut, C.P.; Eschle, B.K.; et al. Altered chromosomal topology drives oncogenic programs in SDH-deficient GISTs. Nature 2019, 575, 229-233. [CrossRef]

18. Casali, P.G.; Abecassis, N.; Aro, H.T.; Bauer, S.; Biagini, R.; Bielack, S.; Bonvalot, S.; Boukovinas, I.; Bovee, J.; Brodowicz, T.; et al. Gastrointestinal stromal tumours: ESMO-EURACAN clinical practice guidelines for diagnosis, treatment and follow-up. Ann. Oncol. 2018, 29, iv267. [CrossRef]

19. Prakash, S.; Sarran, L.; Socci, N.; DeMatteo, R.P.; Eisenstat, J.; Greco, A.M.; Maki, R.G.; Wexler, L.H.; LaQuaglia, M.P.; Besmer, P.; et al. Gastrointestinal stromal tumors in children and young adults: A clinicopathologic, molecular, and genomic study of 15 cases and review of the literature. J. Pediatr. Hematol. Oncol. 2005, 27, 179-187. [CrossRef]

20. Miettinen, M.; Lasota, J.; Sobin, L.H. Gastrointestinal stromal tumors of the stomach in children and young adults: A clinicopathologic, immunohistochemical, and molecular genetic study of 44 cases with long-term follow-up and review of the literature. Am. J. Surg. Pathol. 2005, 29, 1373-1381. [CrossRef]

21. Rutkowski, P.; Magnan, H.; Chou, A.J.; Benson, C. Treatment of gastrointestinal stromal tumours in paediatric and young adult patients with sunitinib: A multicentre case series. BMC Cancer 2017, 17, 717. [CrossRef] [PubMed]

22. Benesch, M.; Leuschner, I.; Wardelmann, E.; Thielen, M.; Schmid, I.; Kontny, U.; Ebetsberger, G.; Frey, E.; Graf, N.; Schneider, D.T.; et al. Gastrointestinal stromal tumours in children and young adults: A clinicopathologic series with long-term follow-up from the database of the Cooperative Weichteilsarkom Studiengruppe (CWS). Eur. J. Cancer 2011, 47, 1692-1698. [CrossRef] [PubMed]

23. Rubin, B.P.; Heinrich, M.C.; Corless, C.L. Gastrointestinal stromal tumour. Lancet 2007, 369, $1731-1741$. [CrossRef]

24. Agaimy, A.; Wunsch, P.H. Lymph node metastasis in gastrointestinal stromal tumours (GIST) occurs preferentially in young patients $<$ or $=40$ years: An overview based on our case material and the literature. Langenbecks Arch. Surg. 2009, 394, 375-381. [CrossRef]

25. Rege, T.A.; Wagner, A.J.; Corless, C.L.; Heinrich, M.C.; Hornick, J.L. “Pediatric-type” gastrointestinal stromal tumors in adults: Distinctive histology predicts genotype and clinical behavior. Am. J. Surg. Pathol. 2011, 35, 495-504. [CrossRef]

26. Younger, E.; Husson, O.; Bennister, L.; Whelan, J.; Wilson, R.; Roast, A.; Jones, R.L.; van der Graaf, W.T. Age-related sarcoma patient experience: Results from a national survey in England. BMC Cancer 2018, 18, 991. [CrossRef] 
27. De Rojas, T.; Kasper, B.; Van der Graaf, W.; Pfister, S.M.; Bielle, F.; Ribalta, T.; Shenjere, P.; Preusser, M.; Frohling, S.; Golfinopoulos, V.; et al. EORTC SPECTA-AYA: A unique molecular profiling platform for adolescents and young adults with cancer in Europe. Int. J. Cancer 2019. [CrossRef]

28. Ferrari, A.; Thomas, D.; Franklin, A.R.; Hayes-Lattin, B.M.; Mascarin, M.; van der Graaf, W.; Albritton, K.H. Starting an adolescent and young adult program: Some success stories and some obstacles to overcome. J. Clin. Oncol. 2010, 28, 4850-4857. [CrossRef]

29. Kang, G.; Park, Y.S.; Jung, E.S.; Joo, M.; Kang, M.S.; Ahn, S.; Kang, G.H.; Kim, K.M. Gastrointestinal stromal tumors in children and young adults: A clinicopathologic and molecular genetic study of 22 Korean cases. APMIS 2013, 121, 938-944. [CrossRef]

30. Fero, K.E.; Coe, T.M.; Fanta, P.T.; Tang, C.M.; Murphy, J.D.; Sicklick, J.K. Surgical management of adolescents and young adults with gastrointestinal stromal tumors: A US population-based analysis. JAMA Surg. 2017, 152, 443-451. [CrossRef]

31. Farag, S.; van Coevorden, F.; Sneekes, E.; Grunhagen, D.J.; Reyners, A.K.L.; Boonstra, P.A.; van der Graaf, W.T.; Gelderblom, H.J.; Steeghs, N. Elderly patients with gastrointestinal stromal tumour (GIST) receive less treatment irrespective of performance score or comorbidity-A retrospective multicentre study in a large cohort of GIST patients. Eur. J. Cancer 2017, 86, 318-325. [CrossRef] [PubMed]

32. Boikos, S.A.; Pappo, A.S.; Killian, J.K.; LaQuaglia, M.P.; Weldon, C.B.; George, S.; Trent, J.C.; von Mehren, M.; Wright, J.A.; Schiffman, J.D.; et al. Molecular subtypes of KIT/PDGFRA wild-type gastrointestinal stromal tumors: A report from the national institutes of health gastrointestinal stromal tumor clinic. JAMA Oncol. 2016, 2, 922-928. [CrossRef] [PubMed]

33. Weldon, C.B.; Madenci, A.L.; Boikos, S.A.; Janeway, K.A.; George, S.; von Mehren, M.; Pappo, A.S.; Schiffman, J.D.; Wright, J.; Trent, J.C.; et al. Surgical management of wild-type gastrointestinal stromal tumors: A report from the national institutes of health pediatric and wildtype gist clinic. J. Clin. Oncol. 2017, 35, 523-528. [CrossRef] [PubMed]

34. Boonstra, P.A.; Steeghs, N.; Farag, S.; van Coevorden, F.; Gelderblom, H.; Grunhagen, D.J.; Desar, I.M.E.; van der Graaf, W.T.A.; Bonenkamp, J.J.; Reyners, A.K.L.; et al. Surgical and medical management of small bowel gastrointestinal stromal tumors: A report of the Dutch GIST registry. Eur. J. Surg. Oncol. 2019, 45, 410-415. [CrossRef] [PubMed]

35. Soomers, V.L.M.N.; Husson, O.; Young, R.J.; Desar, I.M.E.; Van der Graaf, W.T.A. The sarcoma diagnostic interval: A systematic review on length, contributing factors and patient outcomes. ESMO Open 2020, 5. [CrossRef] [PubMed]

36. Van Nederveen, F.H.; Gaal, J.; Favier, J.; Korpershoek, E.; Oldenburg, R.A.; de Bruyn, E.M.; Sleddens, H.F.; Derkx, P.; Riviere, J.; Dannenberg, H.; et al. An immunohistochemical procedure to detect patients with paraganglioma and phaeochromocytoma with germline SDHB, SDHC, or SDHD gene mutations: A retrospective and prospective analysis. Lancet Oncol. 2009, 10, 764-771. [CrossRef]

37. Miettinen, M.; Lasota, J. Gastrointestinal stromal tumors: Pathology and prognosis at different sites. Semin. Diagn. Pathol. 2006, 23, 70-83. [CrossRef]

(C) 2020 by the authors. Licensee MDPI, Basel, Switzerland. This article is an open access article distributed under the terms and conditions of the Creative Commons Attribution (CC BY) license (http://creativecommons.org/licenses/by/4.0/). 